\title{
In vitro analysis of thermocompaction time and gutta-percha type on quality of main canal and lateral canals filling
}

\section{André Luiz da Costa Michelotto(a) Cacio Moura-Netto(b) \\ Ângela Toshie Araki(c) \\ Eduardo Akisue ${ }^{(d)}$ \\ Abílio Albuquerque Maranhão \\ Moura $^{(b)}$ \\ Gilson Blitzkow Sydney ${ }^{(e)}$}

(a) PhD, Department of Endodontics, Dental School, Universidade Tuiuti do Paraná, Curitiba, PR, Brazil.

(b) $\mathrm{PhD}$, Department of Endodontics, School of Dentistry, University of São Paulo, São Paulo, SP, Brazil.

(c) PhD, Department of Endodontics, Dental School, University of Cruzeiro do Sul, São Paulo, SP, Brazil.

(d) PhD, Department of Endodontics, Dental School, University of Santa Cecília, Santos, SP, Brazil.

(e) PhD, Department of Endodontics, Dental School, Federal University of Paraná, Curitiba, PR, Brazil.

\section{Corresponding author:}

André Luiz da Costa Michelotto

Rua Manoel Eufrásio, 395

Curitiba - PR - Brazil

CEP: 80030-440

E-mail: andremichelotto@hotmail.com

Received for publication on Apr 13, 2010 Accepted for publication on Jul 14, 2010

\begin{abstract}
The aim of this study was to evaluate the quality of filling in main and lateral root canals performed with the McSpadden technique, regarding the time spent on the procedure and the type of gutta-percha employed. Fifty simulated root canals, made with six lateral canals placed two apiece in the cervical, middle and apical thirds of the root, were divided into 5 groups. Group A: McSpadden technique with conventional gutta-percha, performed with sufficient time for canal filling; Group B: McSpadden technique with conventional gutta-percha, performed in twice the mean time used in Group A; Group C: McSpadden technique with TP gutta-percha, performed with sufficient time for canal filling; Group D: McSpadden technique with TP gutta-percha, performed in twice the mean time used in Group C; Group E: lateral condensation technique. Images of the filled root canals were taken using a stereomicroscope and analyzed using the Leica QWIN Pro software for filling material flow, gutta-percha filling extension and sealer flow. Data were analyzed by analysis of variance (ANOVA) and Tukey test $(\mathrm{p}<0.05)$. The best values of penetration in lateral canals in the middle third occurred in the groups where TP gutta-percha was used. However, in the apical third, group B showed the best values. Although a longer time of compactor use allows greater penetration of the filling material into the lateral canals, the presence of voids resulted in bad quality radiographic images, suggesting porosity. The best quality of filling material was observed in Group A (McSpadden technique with conventional Gutta-Percha, performed with sufficient time for root canal filling).
\end{abstract}

Descriptors: Root canal filling materials; Gutta-percha; Root canal obturation.

\section{Introduction}

The final goal of endodontic therapy is a root canal filling that allows impermeability of the system with a non-irritant material that stimulates periapical healing. ${ }^{1}$ Gutta-percha associated with a sealer has been considered the choice material due to good tissue tolerance, good adaptation to root canal walls, satisfactory dimensional stability, radiopacity and easy removal. ${ }^{1}$ The most popular technique for root canal filling is the lateral condensation of gutta-percha, but the absence of homogeneity compromises the technique's sealing ability. ${ }^{1}$

Looking for a more effective technique, Schilder ${ }^{1}$ in 1967 introduced 
the heating and condensation of the gutta-percha, starting a new concept for this phase of endodontic therapy. It is here, through the application of heat, that the plasticization of gutta-percha is achieved, resulting in a homogeneous and best adapted filling to root canal walls. In 1980, McSpadden ${ }^{2}$ showed a compactor concept with a design similar to an inverted Hedströen file that, when activated, allows lateral and apical gutta-percha plasticization and condensation, filling the entire root canal system, enhancing Schilder's principle.

During thermoplasticization with a compactor some problems may occur, such as: compactor fracture, circular movement of the gutta-percha around the compactor without penetration into the root canal, absence of gutta-percha plasticization, extrusion of plasticized gutta-percha through the apical foramen and the presence of voids in the filling material. Compactor fracture is directly related to insufficient speed, excessive apical pressure and invasion of the root canal curvature. The presence of voids is due to excessive compaction. ${ }^{3}$

With the gutta-percha thermocompaction technique, plasticity is an important feature of this material, allowing better adaptation to root canal walls, also acquired through pressure developed during lateral and vertical condensation. ${ }^{4}$ Some special care is needed for conservation of the cones and consequent maintenance of its plasticity over time. The cones must be kept away from light and air, to prevent oxidation that can lead to degradation of the material.

Its crystalline form shows two phases: alpha and beta. Alpha phase is obtained directly from the tree. When heated, the material shows two transitional phases. When the temperature reaches around $46^{\circ} \mathrm{C}$, the beta phase is observed. If heated to higher temperatures $\left(54^{\circ}\right.$ to $\left.60^{\circ} \mathrm{C}\right)$, an amorphous phase is achieved. When slowly cooled, the material crystallizes in the beta phase. So, commercially available gutta-percha is beta phase. This gutta-percha is stable and flexible in ambient temperatures. When heated, no adhesion is observed and a lower flow than in alpha phase is achieved. In alpha phase, in ambient temperatures, the material is fragile, sticky when heated, adherent and with higher flow than in beta phase..$^{5}$ Substance purity can alter its fusion point..$^{6-8}$

Recently, several new products have employed alpha phase to achieve thermocompaction. ${ }^{5}$ As the composition of these materials is an industrial secret, both the alpha phase and the wax addition to get a more plastic material are questioned. As an example of these new types of cones, we find TP guttapercha (Dentsply-Maillefer).

According to the material features it is presumed that the time necessary for its plasticization should be different than that observed for conventional gutta-percha cones, influencing the filling quality. Thus, the aim of the present study was to compare in vitro the quality and flow of TP and conventional gutta-percha, used in conjunction with the McSpadden technique, varying the time of compactor use.

\section{Material and Methods}

For the present study, 50 simulated curved canals with six lateral canals, two in the cervical, middle and apical thirds of each tooth, were made at the Prosthesis Laboratory, Dental School, Federal University of Paraná (UFPR, Curitiba, PR, Brazil) and were selected and divided into five groups.

The sealer used for all groups was Endofill (Dentsply-Maillefer, Ballaigues, Orbe, Switzerland), which was placed into the canals using the master point. ${ }^{9}$ The control group was filled using the lateral condensation technique. All simulated root canals of the experimental groups were filled employing the McSpadden technique, varying the type of gutta-percha and time of compaction. In Group A, simulated root canals were filled with \#50 conventional guttapercha (Dentsply-Maillefer, Ballaigues, Orbe, Switzerland), recording the time needed for filling each sample (mean: $7.6 \pm 1.53$ s). In Group B, simulated canal fillings were performed with the same guttapercha type, spending twice the mean time recorded for group A (mean: $15.2 \pm 1.37$ s). In Groups C and $\mathrm{D}$, the same procedure was employed using the TP gutta-percha (Dentsply-Maillefer, Ballaigues, Orbe, Switzerland). Mean times were $9.6 \pm 1.57 \mathrm{~s}$ and $19.2 \pm 1.64$ s, respectively. TP cones were calibrated with a proper calibrating gauge (Sybron-Kerr, Orange, CA, USA), according to the pattern tips of the 
simulated root canals (\#50). The thermocompactor with a higher tip (\#55) was selected and inserted into the canal, $16 \mathrm{~mm}$ deep. Once the thermocompaction was performed, a cold plugger was used for vertical condensation of the filling material to achieve better adaptation to the canal walls.

For evaluation of penetration of the filling material into lateral canals, images of the simulated canals were taken with a stereomicroscope (Leica Microsystems, Bannockburn, IL, USA), and analyzed using Leica QWIN Pro software (Leica Microsystems, Bannockburn, IL, USA), registering the total length of the lateral root canal, penetration extension of the gutta-percha and extension of flow of the sealing material. The data were submitted to analysis of variance (ANOVA) and Tukey's test $(\mathrm{p}<0.05)$.

The quality of the simulated canal filling was analyzed by three endodontists, previously rated for reliability and agreement correlation. For rating of the professionals, three radiographs were used: one with good quality, one with satisfactory quality and one with bad quality. The collected data were submitted to statistical analysis, using Kappa correlation test for inter-evaluator comparison and the KruskalWallis non-parametric test for score analysis.

\section{Results}

The mean times required for thermocompaction were: $7.6 \pm 1.53 \mathrm{~s}$ for group $\mathrm{A} ; 15.2 \pm 1.37 \mathrm{~s}$ for group B; $9.6 \pm 1.57 \mathrm{~s}$ for group C; and $19.2 \pm 1.64 \mathrm{~s}$ for group D.

Graph 1 shows the data distribution for Groups A to $\mathrm{E}$, regarding filling material penetration in the middle third of teeth. Graph 2 shows the data distribution for Groups A to E regarding filling material penetration in the apical third of teeth. Through ANOVA ( $p=0.019)$, statistically significant difference was found. Through the Tukey test it was observed that Group D had better values than Group A, regarding filling material penetration in the middle third of teeth. In the apical third, ANOVA $(\mathrm{p}=0.062)$ showed statistically significant difference. Through the Tukey test it was observed that Group B showed better values than Group E.

Graph 3 shows the data distribution of the groups regarding only gutta-percha penetration $(\mathrm{mm})$ in the middle third of teeth.

Regarding subjective analysis, evaluations from the three examiners were tabulated and analyzed through Kappa correlation test. This test yielded a result of 0.75 , or $75 \%$, showing high correlation among the examiners. Next, the Kruskal-Wallis non-parametric statistical test was applied, denoting statistically significant difference $(\mathrm{p}=0.05)$. Group E showed the best quality results, and Group D showed the worst quality results.

Graph 4 shows filling quality distribution regarding type of gutta-percha used, and time spent for thermocompaction. The worst results were observed for Group D, due to the absence of good filling quality radiographs and 14 bad filling quality radiographs. In this data analysis the best results were observed for Groups A and E.

\section{Discussion}

The critical function of the root filling is to act as a barrier to infection of the periapical tissues. Based on current biological understanding, the root filling fulfills its role in three ways: blockage of any communication between the oral cavity and periradicular tissues; entombment of any surviving bacterial cells in the root canal system; and prevention of tissue fluid derived from the periapical tissues from reaching bacteria cells in the root canal and thus permitting their survival. ${ }^{10}$

The lateral condensation technique, due to its ease-of-use, safety, and promotion of a radiographically compact filling, is still the most commonly

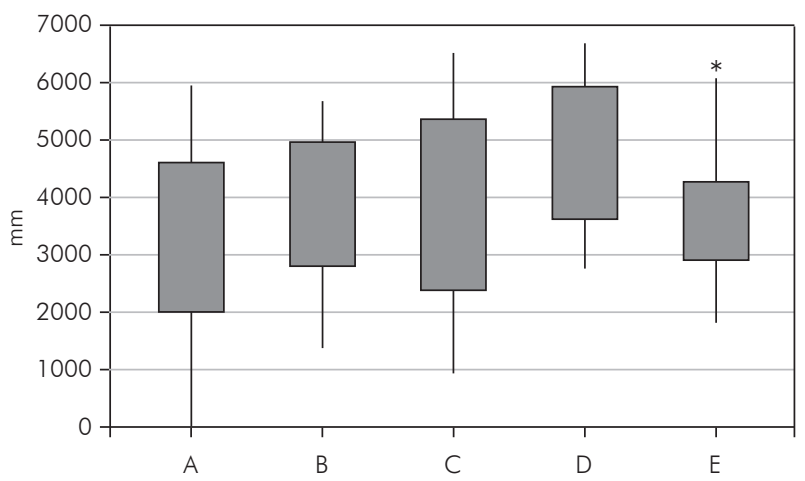

Graph 1 - data distribution of the filling material penetration in the middle third of teeth $(\mathrm{mm})$. 


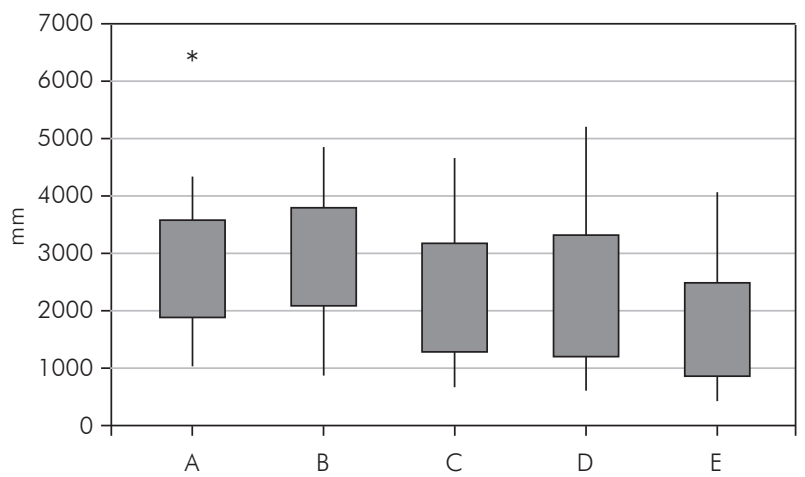

Graph 2 - data distribution of the filling material penetration in the apical third of teeth $(\mathrm{mm})$.

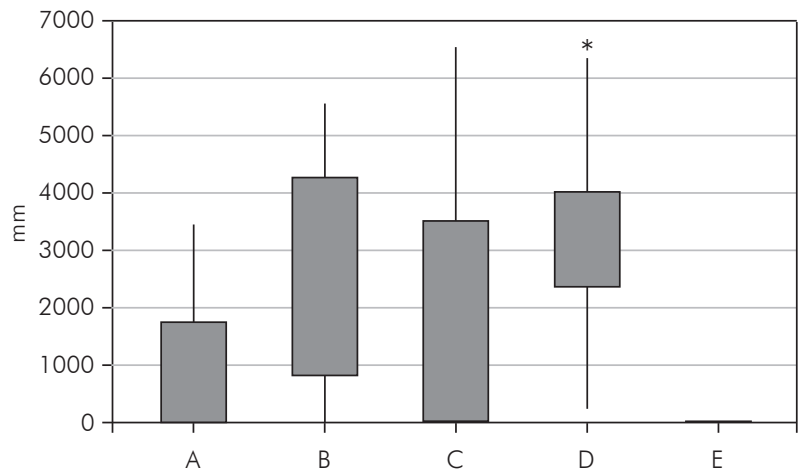

Graph 3 - data distribution of gutta-percha penetration in the middle third of teeth $(\mathrm{mm})$.

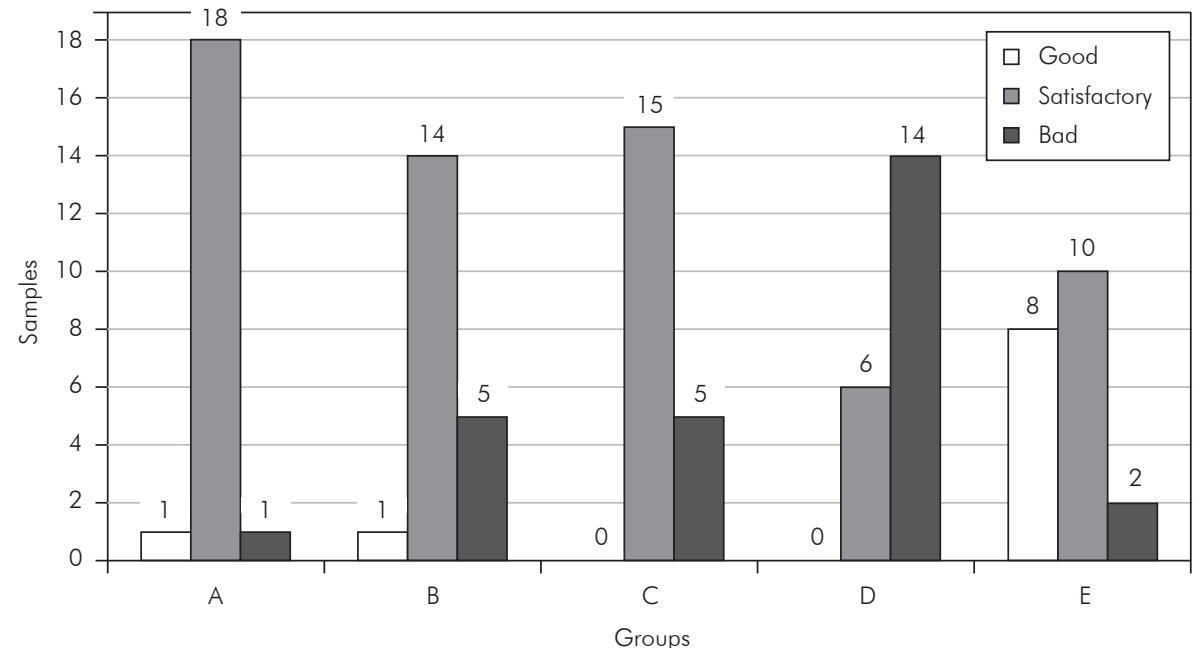

Graph 4 - data distribution of the obturation quality.

used technique for root canal filling. ${ }^{1}$ Nevertheless, the capacity of this technique for totally sealing the root canal system is questionable. Nowadays, thermomechanical compaction and thermally softening the gutta-percha, which is injected into the root canal during filling procedures, are two of the methods for heating gutta-percha. Some authors have shown the superiority of these techniques when compared to lateral condensation. ${ }^{11,12}$ The McSpadden technique is the most simple and practical thermoplasticization filling technique available. When the compactor is activated, the plasticization of the gutta-percha occurs due to the heat generated by attrition, leading to the tridimensional compaction of the material.

One of the questions regarding the use of the McSpadden technique is the time of use of the compac- tor, which must be capable of plasticizing the guttapercha without the formation of voids, which would lead to porous fillings. The commercial availability of alpha phase gutta-percha, named TP gutta-percha, may facilitate thermocompaction due to its higher plasticity, the evaluation of which is the aim of the present study. Literature shows that a greater amount of gutta-percha has been found in TP cones, when compared to eight other commercial brands. ${ }^{13}$

The use of resin for the simulated root canals allowed a standardization of the experiment, eliminating variables among natural teeth. The simulated root canals had lateral canals in the middle and apical thirds, in the bucco-lingual aspect, for evaluation of the filling material penetration. All simulated root canal fillings were performed by a qualified endodontist, by whom the technique is commonly 
used.

Regarding sealing penetration, our results suggest that, in the middle thirds, the best results were observed in the group performed using the McSpadden technique and TP gutta-percha with twice the time used for filling simulated canals in Group A. In the apical thirds, statistically significant difference was observed only between Groups B and E (lateral condensation technique - control). The McSpadden technique with conventional gutta-percha, spending twice the mean time of thermocompactor use, led to higher values of sealing penetration.

Regarding gutta-percha penetration in lateral canals of the middle thirds, statistically significant differences were observed between groups, and statistical tests pointed to higher penetration using the McSpadden technique with TP gutta-percha performed with twice the time of thermocompactor use. The control group showed lower values of penetration.

The higher values of penetration of the sealing material and gutta-percha observed for Group D corroborates the higher plasticity of TP gutta-percha over conventional gutta-percha, which is in accordance with the findings of Tanomaru Filho et al. ${ }^{4}$ The longer time of thermocompactor use also influenced the flow of the filling material in lateral root canals.

None of the Groups showed penetration of gutta-percha in the apical thirds. This confirms a limitation of the compactor, which plasticizes the gutta-percha only a few millimeters from its point. This was visually confirmed as there was no compact mass of filling material observed in this region, making it possible to distinguish the gutta-percha from the sealer material. These results are similar to those found by Tagger et al. ${ }^{14}$ 1984, where they state that the heat action generated by the compactor is only effective 1 to $2 \mathrm{~mm}$ beyond its active extremity. For this reason, a hybrid technique was suggested, using lateral condensation in the apical third followed by thermocompaction in the middle and cervical thirds. ${ }^{15}$

So, based on these results and on those found in literature, ${ }^{16-18}$ it is recommended that, in straight root canals, the compactor penetration be focused 2 to $3 \mathrm{~mm}$ before the working length; and, in curved root canals, this depth be limited to the beginning of the curvature, to avoid condenser fracture.

For analysis of the radiographic quality of the fillings, radiographs of the simulated root canals were taken. Three experienced endodontists were invited to be the evaluators for the analysis. For interrater correlation of the observers, three radiographs, one with good quality (without porosity), another with satisfactory quality (few porosities) and one with bad quality (several porosities) were discussed. Those with the fillings identified as good and satisfactory were defined as clinically acceptable. The data resulting from the three evaluators were tabulated and analyzed. Results showed statistically significant differences between groups, leading to the conclusions that, for subjective analysis of the radiographic images, the best results were observed in Group E (lateral condensation technique) and Group A (McSpadden technique with conventional gutta-percha in normal time); and the worst results were observed in simulated root canals of Group D, where the McSpadden technique with TP gutta-percha was employed with twice the time of use of the compactor.

This way, it was observed that TP gutta-percha has higher penetration capacity when compared to conventional gutta-percha; however, it also showed the worst results regarding quality of the radiographic image of the fillings. The longer time of compactor use inside the root canal led to higher penetration of the filling material in the lateral canals, but resulted in porosity, leaving low quality fillings. This result is in accordance with others in the literature ${ }^{12,18-19}$ which suggest that the compactor must be applied to the root canal only for the necessary time for gutta-percha plasticization and filling of the root canal.

\section{Conclusions}

Under the conditions of this study, TP guttapercha showed higher plasticity than conventional gutta-percha. The longer time spent for compaction promoted greater penetration of filling material inside the root canals; however, also resulting in more failures. 


\section{References}

1. Schilder H. Filling root canals in three dimensions. Dent Clin North Am. 1967 Nov:723-44.

2. McSpadden JT. Self instruction manual. London: Ash Dentsply; 1980.13 p.

3. Pereira AJA, Fidel RAS, Fidel SR, Souza MIC. Avaliação radiográfica do deslocamento apical da obturação de canais radiculares promovido pelo compactador de McSpadden na técnica híbrida de Tagger. Rev Bras Odontol. 1999 Nov-Dec;56(6):2647.

4. Tanomaru Filho M, Silveira GF, Bier CAS, Tanomaru JMG. [Avaliação da capacidade de termoplastificação de diferentes cones de guta-percha e resilon resumo Ia 047]. Braz Oral Res. 2005;19 Suppl:50.

5. Maniglia-Ferreira C, Gurgel-Filho ED, Silva Jr JB, Paula RC, Feitosa JP, Gomes BP, et al. Brazilian gutta-percha points. Part II: thermal properties. Braz Oral Res. 2007 Jan-Mar;21(1):2934.

6. Cohen S, Burns RC. Pathways of the pulp. $8^{\text {th }}$ ed. St. Louis: Mosby; 2002. 1029 p.

7. Goodman A, Schilder H, Aldrich W. The thermo mechanical properties of guta-percha II. The history and molecular chemistry of guta-percha. Oral Surg Oral Med Oral Pathol. 1974 Jun;37(6):954-61.

8. Lopes HP, Siqueira JFS. Endodontia: Biologia e técnica. $2^{a}$ ed. Rio de Janeiro: Guanabara Koogan;, 2004. 964 p.

9. Oddoni PG, Mello I, Coil JM, Antoniazzi JH. Coronal and apical leakage analysis of two different root canal obturation systems. Braz Oral Res. 2008 Jul-Sep;22(3):211-5.

10. Orstavik D, Pitt Ford T. Essential Endodontology. $2^{\text {nd }}$ Ed. Blackwell Munksgaard; 2007. 478 p.
11. Guimarães AMG, Silveira FF, Brito Jr. M, Nunes E. Correção da obturação do sistema de canais radiculares empregando a técnica híbrida de Tagger. Relato de caso. JBC. 2004 JanMar;8(43):37-40.

12. Moraes IG, Betti LV, Kotsubo AM, Yoshizawa MT. Técnica híbrida de Tagger: o melhor nível de atuação do compactador. RGO 2000 Jul-Sep;48(3):141-44.

13. Maniglia-Ferreira C, Silva Jr JB, Paula RC, Feitosa JP, Cortez DG, Zaia AA, et al. Brazilian gutta-percha points. Part I: chemical composition and X-ray diffraction analysis. Braz Oral Res. 2005 Jul-Sep;19(3):193-7.

14. Tagger M, Tamse A, Katz A, Korzen B. Evaluation of the apical seal produced by a hybrid root canal filling method, combining lateral condensation and thermatic compaction. J Endod. 1984 Jul;10(7):299-303.

15. Lipski M. Root surface temperature rises in vitro during root canal obturation using hybrid and microseal techniques. J Endod. 2005 Apr;31(4):297-300.

16. Harris GZ, Dickey DJ, Lemon RL, Luebke RG. Apical Seal: McSpadden vs. lateral condensation. J Endod. 1982 Jun;8(6):273-6.

17. Kerekes K, Rowe AH. Thermo mechanical compaction of gutta percha root filling. Int Endod J. 1982 Jan;15(1):27-35.

18. Tagger M, Tamse A, Katz A. Efficacy of apical seal of engine plugger condensed root canal fillings- leakage to dyes. Oral Surg Oral Med Oral Pathol. 1983 Dec;56(6):641-6.

19. Moraes IG, Berbert A, Bramante CM, Bernardinelli N, Garcia RB, Kuga MC. Técnicas híbridas de obturação de canais radiculares. RGO, 1989 Oct-Dec;37(4):266-68. 